\title{
ИЗУЧЕНИЕ МОРДОВСКОГО ПЕСЕННОГО ФОЛЬКЛОРА В РАБОТАХ ИССЛЕДОВАТЕЛЕЙ ХІХ-ХХІ ВЕКОВ
}

\section{THE STUDY OF MORDOVIAN SONG FOLKLORE IN THE WORKS OF RESEARCHERS OF THE XIX-XXI CENTURIES}

E. Modina

Summary: Mordva is one of the many Finno-Ugric peoples living both on the territory of the Russian Federation and beyond its borders. The main habitat is located between the Volga and Sura rivers. This nation has a long history and rich musical folk culture. A large number of legends and traditions are in the treasury of the Erzya and Moksha folk wisdom. From the earliest times, various scientists - ethnographers, researchers of folklore sought to convey the knowledge of the past. At first, these were only collections of poems. Then, thanks to the advent of the phonograph, the first music collections began to appear. Over time, notation of musical samples of culture developed, and the first multichannel tape recorders appeared to replace the phonograph. The recording of song folklore acquired a more accurate transcript. Voices began to be recorded on 3 8 , and sometimes even ten staves. Such recordings already conveyed the movement of each voice leading. In the songs, it was possible to highlight certain patterns of the plexus of voices.

This article is devoted to the study of Mordovian song folklore in the works of Russian and foreign researchers of the XIX-XXI centuries. Among folklorists, the work highlights the most famous figures who have made an invaluable contribution to the preservation of traditional folk culture. The article introduces their works, which most fully reveal the world of Mordovian song folklore. Among the works you can find both early and later - from ancient ancient poems to highly accurate musical multichannel transcripts, allowing you to professionally analyze the movement of each voice.

Keywords: folklore, traditions, researcher, folklorist, ethnographer, musical - song, collection, Mordovians, Erzya, Moksha.

\author{
Модина Екатерина Олеговна \\ Преподаватель, Мордовский государственный \\ университет им. Н.П. Огарева, г. Саранск \\ folk-katj@mail.ru
}

Аннотация: Мордва - один из многочисленных финно-угорских народов, проживающих, как на территории Российской Федерации, так и за ее пределами. Основной ареал обитания находится в междуречье Волги и Суры. Этот народ имеет длинную историю и богатейшую музыкальную народную культуру. Большое количество легенд и преданий находится в сокровищнице народной мудрости эрзян и мокшан. С ранних времен, разные ученые - этнографы, исследователи фольклора стремились передать знания прошлых лет. Вначале это были лишь сборники со стихотворениями. Затем, благодаря появлению фонографа, стали появляться первые нотные сборники. Со временем, нотирование музыкальных образцов культуры развивалось, и на смену фонографу, появились первые многоканальные магнитофоны. Запись песенного фольклора приобрело более точную расшифровку. Голоса начали записываться на 3-х - 8-ми, а порой и на десяти нотных станах. Такие записи уже передавали движение каждого голосоведения. В песнях можно было выделять определенные рисунки сплетения голосов.

Данная статья посвящена изучению мордовского песенного фольклора в трудах русских и зарубежных исследователей XIX-XXI веков. Среди фольклористов, в работе выделяются наиболее известные деятели, которые внесли неоценимый вклад в сохранение традиционной народной культуры. Статья знакомит с их работами, которые наиболее полно раскрывают мир песенного фольклора мордвы. Среди работ можно встретить, как ранние, так и более поздние - от древних старинных стихотворений, до высоко точных музыкальных многоканальных расшифровок, позволяющих профессионально анализировать движение каждого голоса.

Ключевые слова: фольклор, традиции, исследователь, фольклорист, этнограф, музыкально - песенный, сборник, мордва, эрзя, мокша.

ловича Шёгрена (1794-1855) [6]. Он являлся академиком, путешественником, историком, этнографом и считается основателем финно-угроведения. Хотя сам он и шведского происхождения, его больше знают, как Российского языковеда. В своей работе «Записки Императорской Петербургской академии наук», которая была опубликована по материалам экспедиции 1827-1829 гг., он представляет народы (их традиции, обряды, песни), которые были до этого не так известны: зыряне, еми, чуди, ингерманландцы, мордва и др.

Па́вел Ива́нович Ме́льников (псевдоним: Андре́й Пече́рский, также известен как Ме́льников-Пече́рский 
(1818-1883) - русский писатель-реалист, публицист, этнограф-беллетрист [7-10]. Его работа «Очерки мордвы» 1867 г. Интересна тем, что он не противопоставляет мордву-эрзю и мордву -мокшу русским, а делает их равными. Он посвятил не мало работ именно мордовскому народу: «Нижегородская мордва», «Общественные моления эрзян», «Эрзянская свадьба», «Мокшанская свадьба» (1851).

Хотелось бы так же выделить венгерского ученого Антала Регули (1819-1858) - один из основоположников венгерского финно-угороведения, лингвист и этнограф [1]. Он совершил путешествие по Уралу от Перми до берега Северного Ледовитого океана и обратно, где собирал этнографические и лингвистические материалы по марийцам, эрзянам, манси и ханты. Все записи находятся в этнографическом музее в г. Зирц (Венгрия). Они являются очень уникальными по своему содержанию, так как это единственные записи, сделанные на звукозаписывающие машины в 19 веке.

Следующим собирателем и исследователем являлся Алексе́й Алекса́ндрович Ша́хматов (1864-1920) - лингвист и историк, русский филолог, основоположник исторического изучения русского языка, древнерусского летописания и литературы, фольклорист-диалектолог и этнограф. Его работа «Мордовский этнографический сборник» 1910 г. в. до сих пор является ценным научным трудом в области фольклористики. В ней он представляет древние тексты мордовских песен с. Оркино Саратовского уезда. Эти тексты ценны именно своей художественной содержательностью. Они передают всю поэтическую красоту национального языка.

Среди финских ученых также есть исследователи, которые обратили свое творчество на мордовскую музыкальную культуру. Первый из них это Хе́йкка Па́асонен (1865-1919) - финский языковед, фольклорист и этнолог [13-14]. В его исследованиях по мордовскому фольклору встречаются такие музыкальные образцы, как древние архаичные песни, содержащие в себе семейно-бытовую, мифологическую, обрядовую и календарную тематику. Но, к сожалению, записи мордовских песен представляли собой лишь текстовой материал и в связи с этим, второй финский исследователь решил восполнить этот пробел и съездить в экспедицию и записать мелодии к этим текстам.

Армас Вайсянен (1890-1969) - является одним из зачинателей мордовской этномузыкологии, он один из первых использовал многоканальные записи песен. «Mordwinische Melodien» это капитальный научный труд, выпущенный финским исследователем в 1948 году по материалам экспедиции 1914 года в самарскую губернию [3]. В нее вошли 143 песенные мелодии и 59 инструментальных наигрышей. Эти многоканальные записи песен находятся в свободном доступе и исполняются мужским ансамблем, что оказалось весьма интересным. Мужская традиция исполнения эрзянских и мокшанских песен была уникальна, так как до момента выпуска работы она считалась утерянной. Гармонические созвучия в мужской транскрипции, являлись информационными донорами в отличие от современного музыкального творчества. С первых звуков можно представить быт, местность, менталитет и картину мира общества, связь с которым в настоящее время давно утеряна. Вайсянен первым отметил разнообразие стилевых и жанровых видов мордовских песен, наличие уникального многоголосия, взаимосвязь напева и текста песен.

Макар Евсевьевич Евсевьев (Кобаев) (1864-1931) мордовский ученый просветитель и педагог [4]. Он написал первые буквари для мордвы-эрзи и мордвы-мокши. Его работы являются достоянием мордовского народа. С 1892 года по 1931 год работал над созданием подробного описания его большого труда «Мордовская свадьба». На основе его исследований, после его смерти выходит в 5-ти томах работа «Избранные труды» М.Е. Евсевьева.

Всесторонне исследовал эпическую мордовскую песню Андрей Иванович Маскаев (1907-1975) - фольклорист, литературовед, доктор филологии, профессор [5]. Он сравнивал эпический жанр мордвы с балладами. Его труды: «Мордовские эпические песни на сказочные сюжеты», «Мотивы сюжета «Девушка и смерть» в мордовском фольклоре», «О мордовском фольклоре периода Великой отечественной войны», «Славяно-мордовские связи по материалам эпической песни» и др.

Михаил Иванович Чувашов (1909-1973) - эрзянский фольклорист, этнограф, краевед [15]. Он занимался сбором музыкального фольклора в Поволжье и Приуралье. Его работы: «Мордовские (эрзянские) причитания», «Духовное наследие народов Поволжья: живые истоки» (1-2 тт.) и др. Он всю свою жизнь посвятил собиранию и изучению эрзянского фольклора.

Кафтаськин Лука Семенович (1911-1977) - фольклорист, критик и литературовед [12]. С деятельностью Луки Семеновича связаны яркие страницы становления мордовского фольклора. Он был талантливым собирателем устного народного творчества, подлинным знатоком и ценителем, неутомимым пропагандистом и кропотливым исследователем. Его работы: «Творчество современных мордовских сказителей» (1951), «Мордовские народные песни» (1955), «мордовская народная песня (1957), «Эрзя-мокшонь морот, сказт ды балладат» (1958), «Устно-поэтическое творчество мордовского народа» Т 1, «Эпические и лиро-эпические песни (1963), «Устнопоэтическое творчество мордовского народа» Т 7 ч. 2, «Эрзянские причитания-плачи» (1972) и др.

Евгений Владимирович (Вольдемарович) Гиппиус (1903-1985) - советский музыковед и музыкальный эт- 
нограф; кандидат исторических наук, доктор искусствоведения, профессор. Также посвятил свои труды изучению народной песни. Он участвовал в этнографических экспедициях, собирая также и мордовские песни. Он является редактором трудов Н. И. Бояркина «Памятники мордовского народного творчества».

Георгий Иванович Сураев-Королев (1922-2000) фольклорист, композитор [11]. Он был не только теоретиком, но и практиком. Под его руководством находился фольклорный ансамбль «Келу», который и по настоящее время носит его имя. Его работы по материалам экспедиций: «Мордовские народные песни» (1957), «Мордовские народные песни» (1969) и др. Он брал основу всех своих сочинений в народной песне. Им написано не мало произведений по мотивам национальных образцов народного творчества.

Огромный вклад в развитие национальной культуры внес Николай Иванович Бояркин (1947 по настоящее время). Член Союза композиторов России, Заслуженный деятель искусств РФ, Им изданы «Памятники мордовского народного творчества) [2]. Это большой труд по изучению национальной эрзянской и мокшанской песни. Все песни записаны многоконально и имеют в своей структуре от трех до десяти голосов. Это позволяет анализировать народную песню изнутри, рассматривая переплетения голосов и проникать в каждую идейно-ху- дожественную музыкальную линию.

Анализ музыкального фольклора нуждается в более детальном исследовании, так как зашифрованная в нем информация представляет особый интерес ученых.

Проблема изучения картины мира в отечественной культурологии, в настоящее время, является актуальной. Степень изученности данной проблематики с каждым годом продолжает увеличиваться и развиваться.

Проблемой изучения музыкальной картины мира мордвы - эрьзи и мордвы - мокши занимались многие ученые. Ее рассматривали с поэтической, художественной, философской сторон, пытаясь охарактеризовать и понять менталитет, быт и устои одного из древнейших народов. К семантике понятия «музыкальная картина мира» обращались не многие. Фольклористы, в основном, пытались сохранить музыкальные материалы, расшифровывая их, давая лишь небольшие комментарии к песням. Выпущенные сборники представляют собой сокровищницу мордовской культуры. В них можно выявить музыкальные закономерности, характерные именно мордве - мокше и эрзе.

Подводя итоги всего вышесказанного, можно утверждать, что музыкальная картина мира мордовского народа не является изученной в полной мере. Она требует комплексного подхода со всех сторон.

\section{ЛИТЕРАТУРА}

1. Архипова Н.П., Ястребов Е.В. Как были открыты Уральские горы. - Свердловск, 1990.

2. Бояркин Н.И. Мордовское народное музыкальное искусство / Под. ред. Е.В. Гиппиус. Саранск: Мордов. кн. изд-во, 1983. 184 с.

3. Вяйсянен А.0. Mordwinische Melodien // Suomalais-ugrilainen Seura. - Хельсинки, 1948.

4. Евсевьев М.Е. Мордовская свадьба. — Саранск: Мордов. кн. изд-во, 1990. — 384 с.Шахматов, Мордовский этнографический сборник Текст. / сост. А.А. Шахматов. СПб, 1910. - 848 с.

5. Маскаев, А.И. Мордовская народная эпическая песня Текст. / А.И. Маскаев. Саранск: Мордов. кн. изд-во, 1964. - 439 с.

6. Матвеев А.К. А.М. Шёгрен как исследователь субстратной топонимики Русского Севера // Взаимодействие языков: Сб. статей / Учёные записки № 80. Серия филологическая, вып. 8 / Редколл.: Э.Д. Барышникова, Л.В. Доровских, А.К. Матвеев (отв. ред.); Уральский государственный университет имени А.М. Горького, МВ и ССО РСФСР. — Свердловск: УрГУ, 1969. — С. 105-110. - 112 с. - 750 экз. (обл.)

7. Мельников П.И. Очерки мордвы // Русский вестник. - М., 1867. - Т. 69. № 6. - С. 488-521.

8. Мельников П.И. Очерки мордвы // Русский вестник. - М., 1867. - Т. 71. № 9. - С. 217-258.

9. Мельников П.И. Очерки мордвы // Русский вестник. - М., 1867. - Т. 71. № 10. - С. 397-430.

10. Мельников П.И. Полное собрание сочинений П.И. Мельникова (Андрея Печерского). В 14 т. - СПб. ; М.: Т-во М.0. Вольф, 1898. - Т. 12. - 4, 432 с.

11. Сураев-Королев Г.И. Многоголосие и ладовое строение мордовской народной песни: мордов. многоголос. пентатоника / Г.И. Сураев-Королев; [вступ. ст. С.Г. Сураева-Королева]. - Саранск: Изд-во Мордов. ун-та, 2007. - 35, [1] с.; 20 см. - 200 экз.

12. Устно-поэтическое творчество мордовского народа. Т. 4, книга 1. Пословицы, присловья и поговорки / Науч.-иссл. ин-т. яз. лит., истории и экономики при Совете Министров Мордов. АССР. — Саранск, 1967. 375 с.

13. Хайкки Паасонен: Die türkischen Lehnwörter im Mordwinischen // JSFOu XV. Helsinki, 1897.

14. Хайкки Паасонен: Die soqenannten Karataj-Mordwinen oder Karatajen // JSFOu XXI. Helsinki, 1902.

15. Чувашев, М.И. Тейтерень пиянь кудо Текст. // (Девичий дом пива) у эрзян/ М.И. Чувашев // Музыка в обрядах и трудовой деятельности финно-угров: сб. статей / сост. и ред. И. Рюйтел. Таллин, 1986. -С.284-311. 